\title{
URBA NISMO
}

\section{La Anteiglesia de Guecho, en Vizcaya, y su plan de Ordenación urbanística}

Esta Anteiglesia, primeramente rural y labriega, tuvo su casa municipal al lado de la iglesia de Santa María, en cuyo pórtico se reunian los Concejos.

Pasó después a ser centro municipal el pequeño puerto de pescadores, cuando lemanes, mareantes y los primeros indianos dieron vida a la barriada. Su caserío, típico dentro de la Anteiglesia, al extenderse fué subiendo con mayor prestancia por las calles empinadas que tiene de acceso, y que pronto alcanzó la barriada de Algorta.

Como ésta fué creciendo, se erigió en ella en el año 1792 la iglesia de San Nicolás, y a su lado el edificio Ayuntamiento, que hasta 1928 fué el centro vital de esta tercera fase de desenvolvimiento de esta inquieta Anteiglesia.

Paralelamente crecieron, por otro extremo, las barriadas de Las Arenas y la más reciente de Neguri, y en ellas se edificaron iglesias para servir al vecindario, que llegó a tener más importancia numérica que el de los núcleos fundacionales.

En 1892 se edificó la iglesia de San Ignacio en el extremo Sur de la barriada de Algorta y en punto cercano al barrio de Neguri. Resultaba ser el centro geográfico de las barriadas que iban creándose con la llegada de los nuevos núcleos de población, y esta circunstancia vino a decidir el emplazamiento en esta barriada de la Casa Consistorial, suntuoso edificio construído el año 1928, desde cuya fecha ha sido el cuarto y será acaso el último centro de la Anteiglesia, que de rural ha pasado a ser la población suntuaria y residencial de Bilbao. 
En las varias ocasiones que he ocupado cargos municipales er en esta Anteiglesia, pude observar la necesidad apremiante de llegar a una ordenación del plano de urbanización de 1924, que previo un concurso de proyectos, y con ellos a la vista, fué elaborado por e! arquitecto municipal don Ignacio M. Smith.

Basándome en tales necesidades, presenté con fecha 2 de febrero de $\mathbf{1 9 4 6}$ una Moción justificando la necesidad de llegar a una ordenación del plano citado, por el hecho de que el mismo, durante el periodo de vigencia, había experimentado modificaciones en su estructura y contenido, llegándose a suprimir y variar calles, que en sectores determinados habian perturbado las del primitivo proyecto.

Por otra parte, y como en la indicada Moción se expresa, no podian pasar desapercibidas las necesidades actuales, derivadas de un natural incremento de población que constante y regularmente viene a crear necesidades que no pudieron preverse al redactar el antiguo proyecto, sobre todo, tratándose de un Municipio de tipo residencial, en el que los problemas urbanísticos vienen creciendo cada día y se precisan nuevas normas. La citada Moción enfoca otros aspectos que tienen un vital interés para la ordenación urbanística de la Anteiglesia, cuales son: $1 .^{\circ}$ El problema planteado por el trazado del ferrocarril que atraviesa en doble via estrecha la zona urbanizada, con circulaciones de veinte en veinte minutos, que se irán acortando, y que al seccionar buen número de calles hace ya imprescindible hallar solución y establecer los pasos correspondientes; $2 .^{\circ} \mathrm{La}$ perturbación que supone el actual emplazamiento de la estación de Las Arenas, que con su zona de expansión ocupa un considerable sector de dicho barrio en su parte más céntrica y poblada, con la secuela inevitable de división y taponamiento de calles; $3 .^{\circ}$ El tipismo del barrio de pescadores de Algorta, de bellas perspectivas y que es necesario conservar, aun suprimiendo aquellas calles cuyo trazado no sea imprescindible; $4 .^{\circ} \mathrm{La}$ necesidad de respetar las tradicionales entradas de la zona del Castillo o Gazteluzarra, adaptándolas a un sentido urbanístico actual, y $5 .^{\circ} \mathrm{La}$ reducción de la anchura de las calles trazadas sin menoscabo del futuro, ya que ello, además de facilitar grandemente la urbanización, hace más viable el proyecto por resultar menos oneroso. Se decia por fin, que la revisión del plano del arquitecto Smith habia de reducirse a establecer las modificacio. res imprescindibles, a fin de lesionar el menor número de inte.reses. 
El Ayuntamiento, en sesiór de 1 de marzo de 1946, recogiendc el contenido de la precedente Moción, acordó aprobarla en todas sus partes y ponerla en ejecución. En primer lugar se comenzó por hacerla pública, y al efecto, con fecha 12 del mismo mes, se cursó oficio a la Cámara de la Propiedad Urbana, dándole cuenta del acuerdo en cuestión.

Posteriormente, en sesión de·17 de mayo, se dispuso por el Ayun. tamiento solicitar de la Dirección General de Arquitectura el que la misma se encargase, por medio de técnicos especializados en urbanismo, de la redacción del proyecto y de las nuevas ordenanzas de construcción.

Designados por aquel alto Organismo los arquitectos don Pedro Bidagor y don Manuel Muñoz Monasterio para el desarrollo del proyecto, ambos pusieron en su labor un entusiasmo loable y la técnica que les tiene ya consagrados como expertos urbanistas.

Ultimado el Plan, se creyó interesante dar estajo oficial al mismo, y al efecto, el 30 de diciembre de 1947 tuvo lugar una reunión en el Salón de Sesiones de la Casa Consistorial, en la que se hallaban presentes las representaciones más significadas de la Anteiglesia, y anie las cuales el arquitecto señor Muñoz Monasterio hizo una clara exposición del trabajo realizado por el conferenciante, bajo la dirección de don Pedro Bidagor, empleando en su disertación los planos totales y parciales confeccionados.

El señor Muñoz Monasterio dijo, entre otras cosas, que para realizar el trabajo habian tenido dos grandes puntos de apoyo: los planos vigentes, realizados por el arquitecto don Ignacio Smith y aprobados en 1924, y los foto-planos que para el estudio de la ordenación del Gran Bilbao habia hecho el Ayuntamiento de la Villa.

Hizo primero un estudio del plan del señor Smith, al que elogió por el gran sentido que, con arreglo a las ideas de entonces, habia sabido imprimir a su proyecto, y, sobre todo, por la visión del futuro con que estaba concebido.

Guecho presenta las características de un poblado de tipo longitudinal, alineado a lo largo de la costa en un terreno difícil.

Como antecedente de esta exposición que resume lo dicho por el señor Muñoz Monasterio, conviene añadir que la zona urbanizada es de $1.514 .180 \mathrm{~m}^{2}$; la de ensanche, de $2.441 .916 \mathrm{~m}^{2}$, y la rural, de

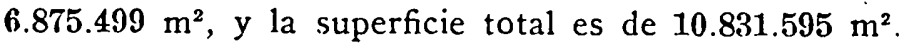


Dentro de la superficie anterior se distinguen las aplicaciones siguientes :

Parques y jardines, 435.000 metros cuadrados; Zona forestal poblada, 330.00 ; ídem sin poblar, 1.010 .000 ; Zona agrícola de secano, 5.137.999; Zona de salvamento, campas y acantilado, 427.500. No hay regadio.

En general, el plan confeccionado abarca las siguientes directrices:

RELIEVE DEL SUELO

En la redacción del proyecto se tienen en cuenta las caracteristi. cas peculiares de cada barrio o zona. La rural en la de Santa María; la de Las Arenas, entre la ria, el puerto exterior y las pequeñas lomas que bruscamente delimitan la llanura del terreno del Este, con varias subzonas en las que predominan los chalets, aislados en unas, como las de Santa Ana y Los Pinares, la de Las Mercedes, con su núcleo comercial, y la de Santa Eugenia, iniciada con construcción de altura; la zona de Neguri, en la que se inician bruscamente las fuertes pendientes en dirección a la de Algorta, formando entre ambas zonas un extenso cerro con dos laderas, una al Oeste, mirando al mar, y otra al Este, tierra adentro, en las que la abundancia de fincas de recreo es manifiesta. Dentro de esta zona se halla la subzona de San Ignacio, donde, junto a los edificios más importantes de la Anteiglesia, Ayuntamiento, Iglesia, etc., se desarrollan las calles comerciales de trazado-regular y anchos reducidos. La zona de Algorta, al Norte de la Anteiglesia, forma una meseta con suave caída hacia la playa de Arrigúnaga, y una subzona, la de Alango, la más alta de la Anteiglesia, con edificaciones de chalets y de altura. Perteneciendo a esta zona de Algorta, hay otras dos subzonas, la de Las Vegas, mirando al Oeste, con paisaje muy ondulado, pero apto para un desarrollo de edificación mixta - chalets y casas de vecindad aisladas-, constituyendo una gran reserva para el futuro, y la del Puerto, de gran tipismo, que es preciso conservar con su edificación algorteña de piedras areniscas y revocos claros.

Al trazar el plan de ordenación de Guecho se ha tenido en cuenta el plan comarcal del Gran Bilbao, que le asigna carácter residencial y que cuida deolibrar que en la Anteiglesia se produzca una invasión industrial fuerte, sin perjuicio de consentir zonas de tolerancia para industria no molesta. 


\section{DEMOGRAFIA}

La población actual de Guecho, de $\mathbf{2 0 . 0 0 0}$ habitantes en ritmo ascendente, hace presuponer se eleve a 45.000 ó 50.000 a fines de siglo. Compuesta en gran parte de personas que residen en la Anteiglesia, pero que se trasladan diariamente a Bilbao y pueblos de la ria a ejercer sus actividades, mediante los excelentes medios de comunicación, no por eso deja de tener importante vida propia, derivada de su estratégica situación como población residencial y de turismo, de su destacado comercio y de la propia vida agrícola.

\section{A C C E S S}

Dos vías de acceso posee hoy Guecho: la carretera que llega a la Avanzada jesde el Valle de Asúa, y la que corre por la margen derecha de la ría, insuficiente para el tráfico intensivo que por ella circula. Se mejora ésta con el ensanchamiento a 20 metros de la calle de Coste, ya llevado a cabo, y el proyecto de continuación hasta su unión con la avenida del Triunfo.

En el proyecto que venimos estudiando se mejoran los accesos con una vía diagonal en el sector de Las Arenas, para incorporarse por una parte a la calle de Santa Ana, y por medio de un ramal que cruzará en paso superior el río Gobela y el ferrocarril, a la vía limitativa; que también se prevé del núcleo por el Este.

Otro acceso previsto es el de la carretera de Asúa, que si se lleva a efecto el ensanche $y$ acortamiento de la carretera, mientras se decide la perforación del túnel del mismo nombre en la demarcación de la capital, habrá de constituir la vía más corta y de inmejorables condiciones para el enlace directo entre Guecho y Bilbao.

\section{FERROCARRII,}

El trazado del mismo tiene una extensión de 6.270 metros y cuenta con las estaciones de Las Arenas, Gobela, Neguri, Algorta y Guecho. Secciona la parte urbanizada de Norte a Sur y sirve a las barriadas citadas, preveyéndose nuevas estaciones y que en futuro plazo funcione a la manera de metropolitano. Pero presenta el incon. veniente del emplazamiento de la estación de Las Arenas, cuya 
zona de maniobra secciona buen número de calles y ocupa un sector de importancia comercial. Se prevé en el plan el desplazamiento de la misma a otro lugar más propicio, mejorándose con ello la relación entre los barrios de Santa Ana y Las Mercedes, según se ve en el croquis que se acompaña.

Se han propuesto dos pasos inferiores en Aiboa y estación de Algorta, y dos superiores en el barrio de Sarri y calle Mercedes en Romo, para servir a las barriadas de ambos lados de la vía.

\section{VIAS PRINCIPALES}

Se proyecta una red de vías principales que han de servir para el desenvolvimiento del tráfico principal y se complementan con las vías secundarias que tienen por finalidad el logro de ía reparcelación adecuada de terrenos.

Las más importantes son: La via límite al Este, que incorporada al nuevo acceso de Bilbao por la ría y delimitando el barrio de Santa Eugenia, corre a lo largo del Parque de Fadura y termina al Norte hasta encontrarse con la vía de cornisa. La de prolongación del paseo de la Avanzada, que parte de la estación de Neguri, pasa por la de Algorta y termina en la playa de Arrigúnaga, uniendo en circunvalación con la calle que desde Arrigúnaga conduce por el Puerto Viejo y playa de Ereaga, a unirse en la Avanzada con la carretera a Las Arenas. La de prolongación de la calle de Las Mercedes, que pasa sobre el Gobela y el ferrocarril y es la arteria principal del ensanche de Santa Eugenia, terminando en la gran plaza de acceso enclavada en la carretera de Asúa, uniendo este barrio y Bilbao fácilmente con el núcleo de Las Arenas. La que partiendo de la calle de Andrés Cortina se incorpora a la cornisa bordeando todo el saliente Norte de Algorta, conduciendo al Parque de San Ignacio, antigua Batería, y las que nacen en la plaza de la avenida de Salsidu y terminan en la plaza semicircular formada a la entrada del Parque de Fadura y en Iturribarri, en el punto denominado por El Pino.

Complemento de estas vias son las que, en sentido Este-Oeste, han de atravesar el ferrocarril por cuatro pasos, de modo que no constituyan obstáculo para las relaciones de unos barrios con otros.

Las vías secundarias, con anchos entre los 8 y los 15 metros, tienden a reparcelar los terrenos y han sido trazadas con el mayor respeto a las alineaciones existentes. 


\section{ZONIFICACION}

Se crean en la parte alta (Algorta) y en la parte baja (Las Arenas), dos núcleos de concentración intensiva comercial, ampliała con las zonas mixtas de casas de vecindad y chalets aislados. Se establece una nueva ordenanza para regulacíón de bloques de altura abiertos, destacándose dos zonas para su aplicación: una en el primer tramo del acceso de Asúa a ambos lados del mismo, y otra al Norte en relación con la vía límite.

Se respeta la Ordenanza de ciudad-jardín, ampliando el número de viviendas en éstos, y se crean las de tolerancia industrial en otras tres zonas: la primera en la zona de Santa Eugenia, la segunda al Nordeste de la Anteiglesia en la zona de Salsidu y la tercera en la zona limite con Lejona (Lamiaco).

El barrio de pescadores de Algorta se respeta integramente, sin perjuicio de mejorar sus condiciones sanitarias.

\section{ALTURA DE EDIFICIOS}

En el estudio de ordenación se ha tenido muy presente el tipo de edificación y número de plantas de viviendas posibles de elevación, habiéndose adoptado una solución de eliminar las retiradas escalonadas que el contorno actual imponia a partir de la tercera planta, llegándose a una fachada vertical y un piso ático, solución que -supone, aparte de la economía, mejor aprovechamiento del solar.

Las alturas al alero han sido aumentadas, autorizándose alturas de 18,40 metros, 15,60 metros y 12,60 metros, contra 14 metros y 12 metros que en las Ordenanzas anteriores se exigian.

También se ha creado una extensa y nueva zona, llamada de «Bloques Abiertos», en cuya zona se permite un mayor aprovechamiento del terreno.

\section{ZONAS DE TURISMO}

Dado el carácter principalmente residencial de Guecho y eminentemente turistico, se han señalado en el plan aquellas zonas y vias cuyo trazado tiende a destacar aquellos puntos de vista que contribuyen a hermosear la Anteiglesia, principalmente la que se desarrolla al borde del mar, a lo largo de la playa de Ereaga, que llegará 
hasta la de Arrigúnaga, creanto una vía de cornisa que parte del Puerto Viejo y por la zona del Parque de Usátegui, actualmente en construcción, llega hasta el escarpe sobre la citada plaza de Arrigúnaga, en el lugar conocido por Alicante.

La Comisión de Ensanche, en sesión celebrada el 17 de enero de 1948, aprobó el proyecto que se reseña anteriormente, y el Ayuntamiento lo hizo suyo en sesión de 4 de marzo, anunciándose profusamente al vecindario, a fin de dar toda clase de facilidades a los afectados para el estudio del proyecto y présentación de las oportunas reclamaciones.

Se han presentado $\mathbf{7 6}$ reclamaciones, que han sido informadas por el arquitecto municipal don Miguel Beáscoa, que ha colaborado eficazmente desde el comienzo. Discutidas con todo detenimiento por la Comisión Especial de Ensanche, elevó una ponencia que acaba de ser aprobada por la Corporación.

Merece la pena destacar la colaboración eficaz que en todo momento ha prestado la Cámara de la Propiedad de Guecho, que ha culminado en un luminoso informe, señalando muchos puntos de coincidencia con el plan suscrito por los arquitectos señores Bidagor y Muñoz Monasterio.

Medición de comparación aproximada, entre las superficies de calles del plano de urbanización antiguo y las calles del nuevo plan de urbanización en las zonas afectadas por éste.

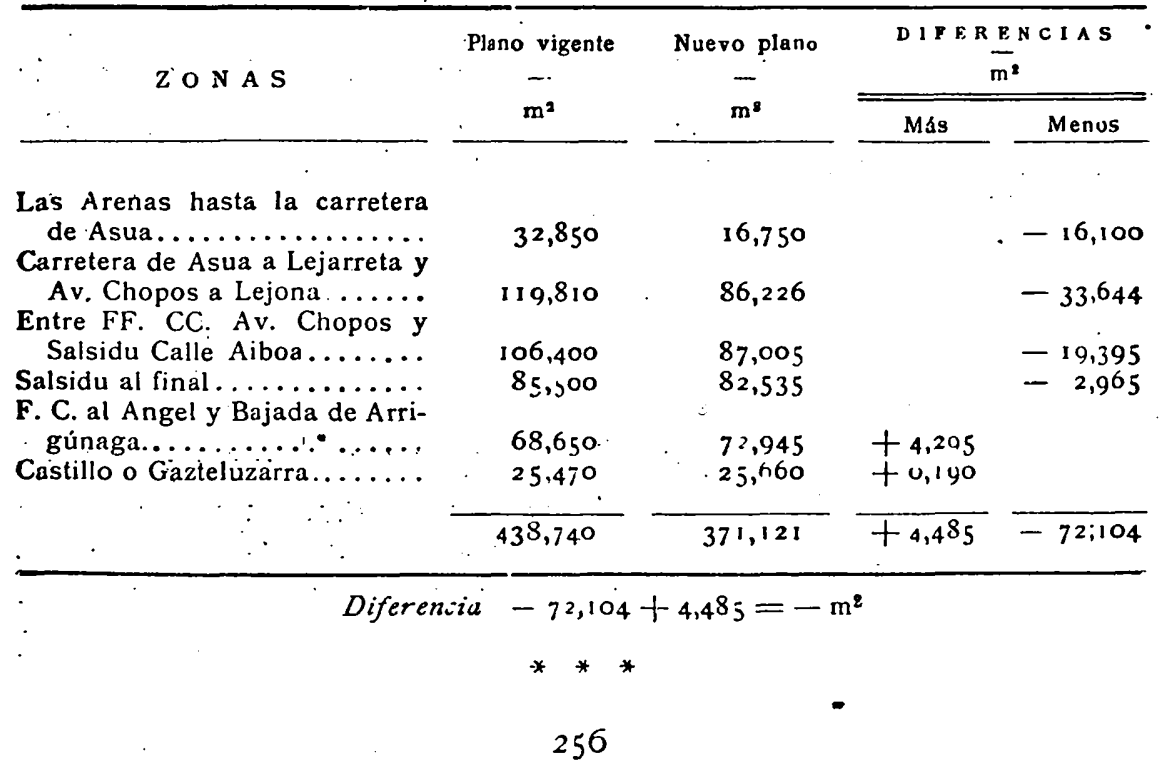




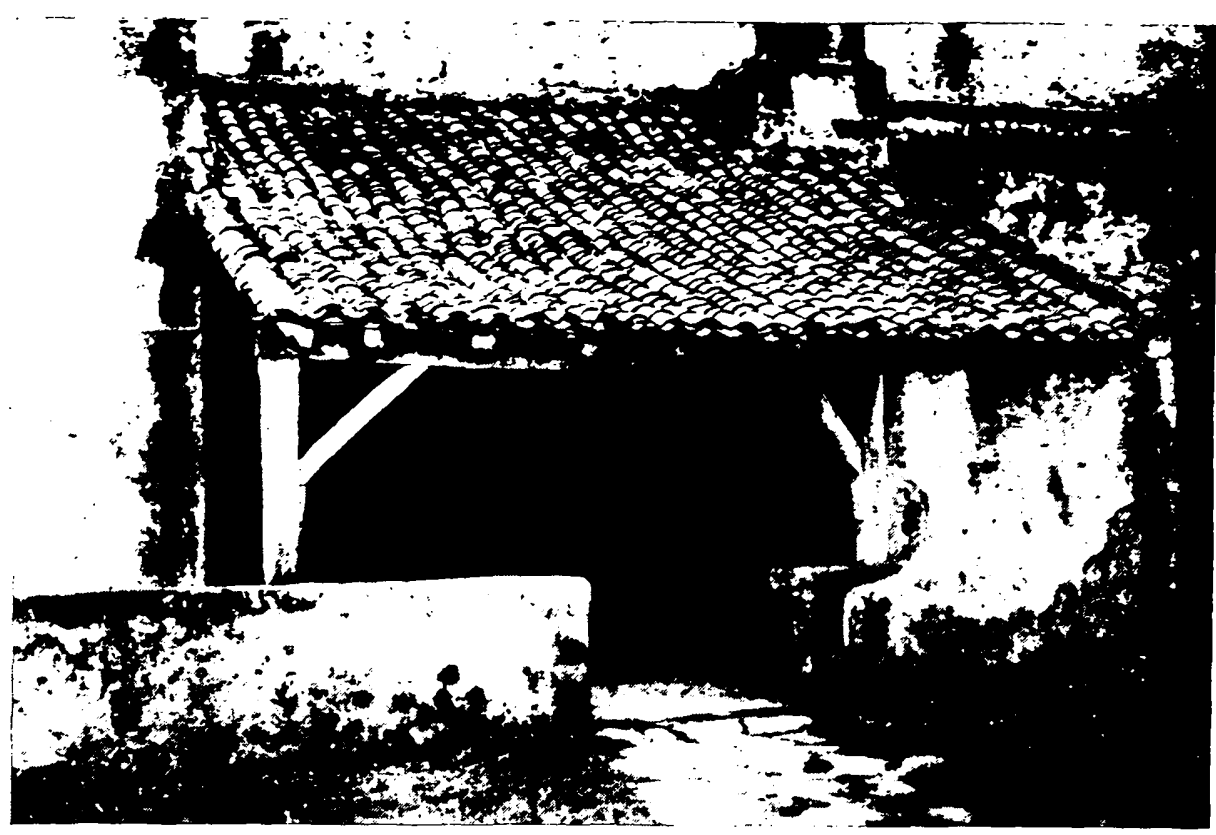

Fig. 1.-Pórtico de la Iglesia de la Asunción de Ntra. Sra. en Santa Maria, en que primitivamente se reunia el Concejo.

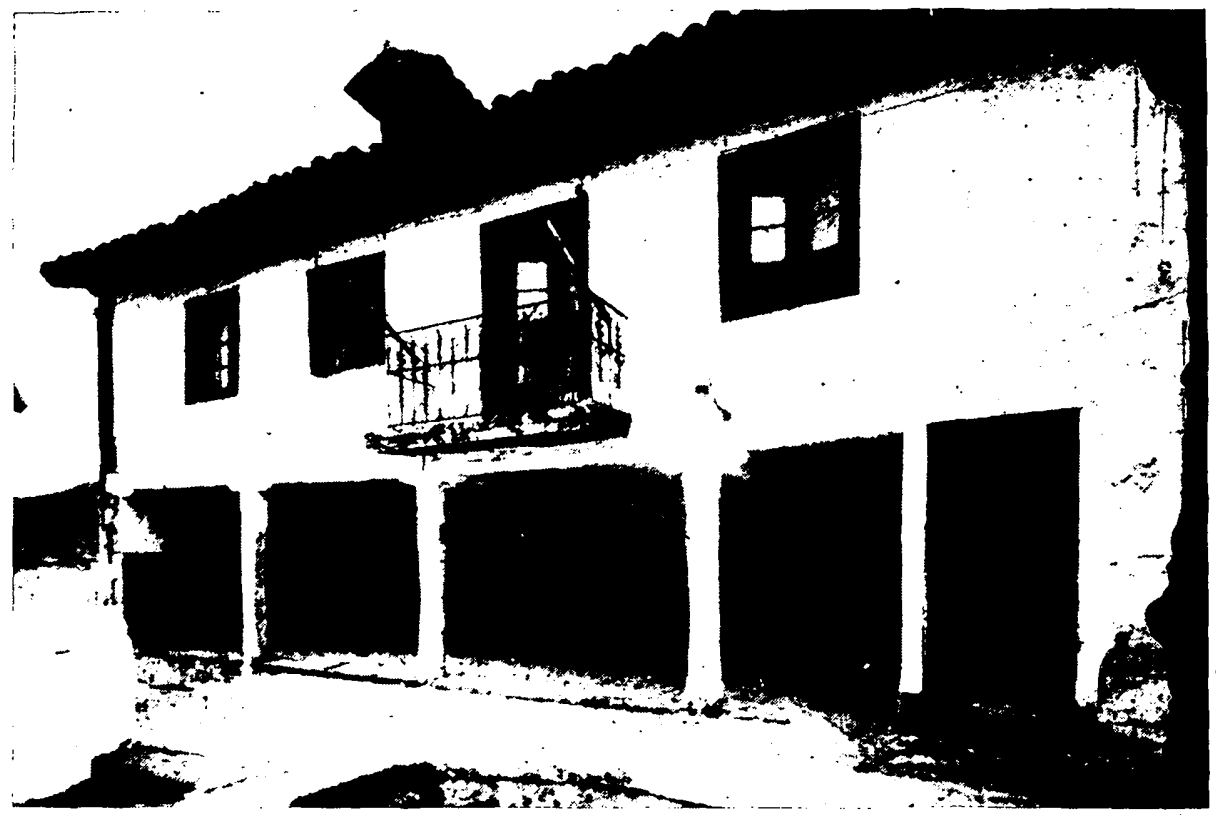

Fig. 2.-Casa llamada "Ediediu, donde celebraba sus deliberaciones el Ayuntamiento cuando fué poblándose la barriada del Puerto de pescadores en Algorta. 


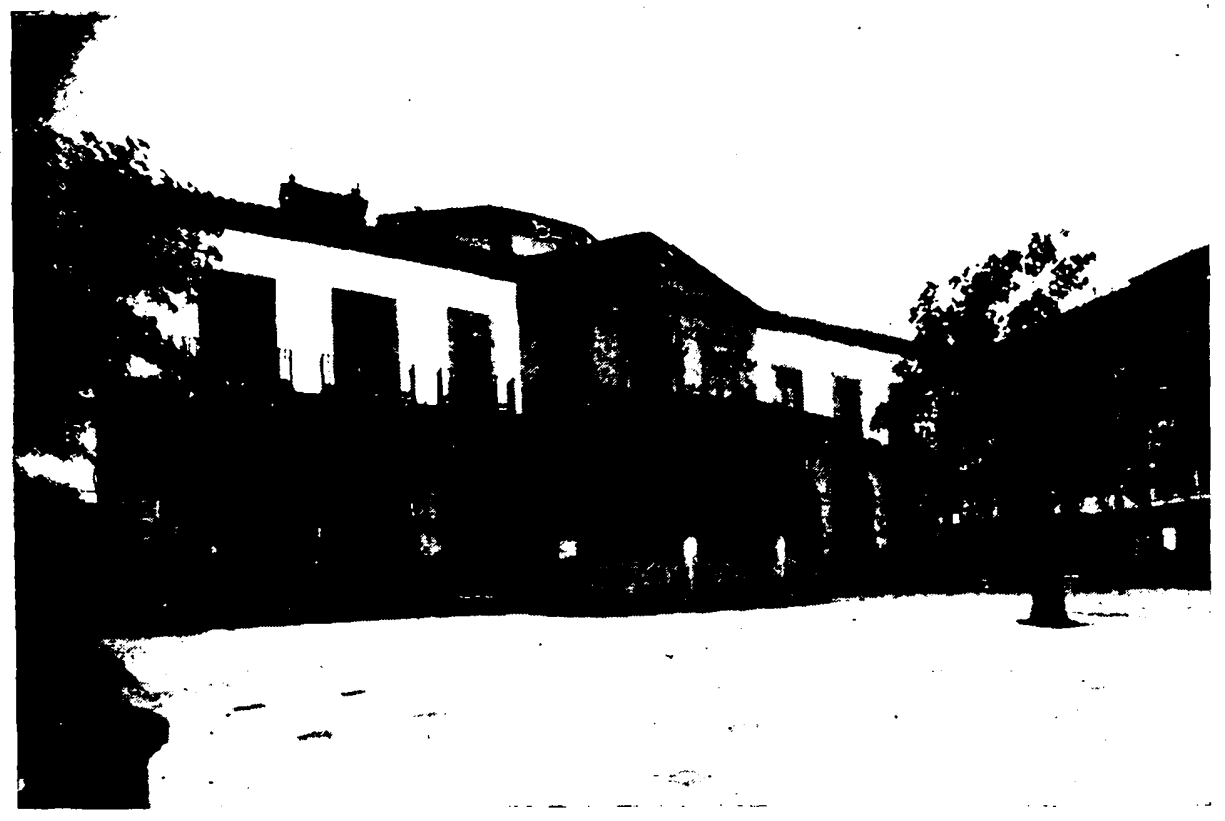

Fig. 3.-Casa Consistorial vieja (hoy Juzgạdo Comarcal) junto a la Iglesia de San Nicolàs, en Algorta (188 I - 1928).

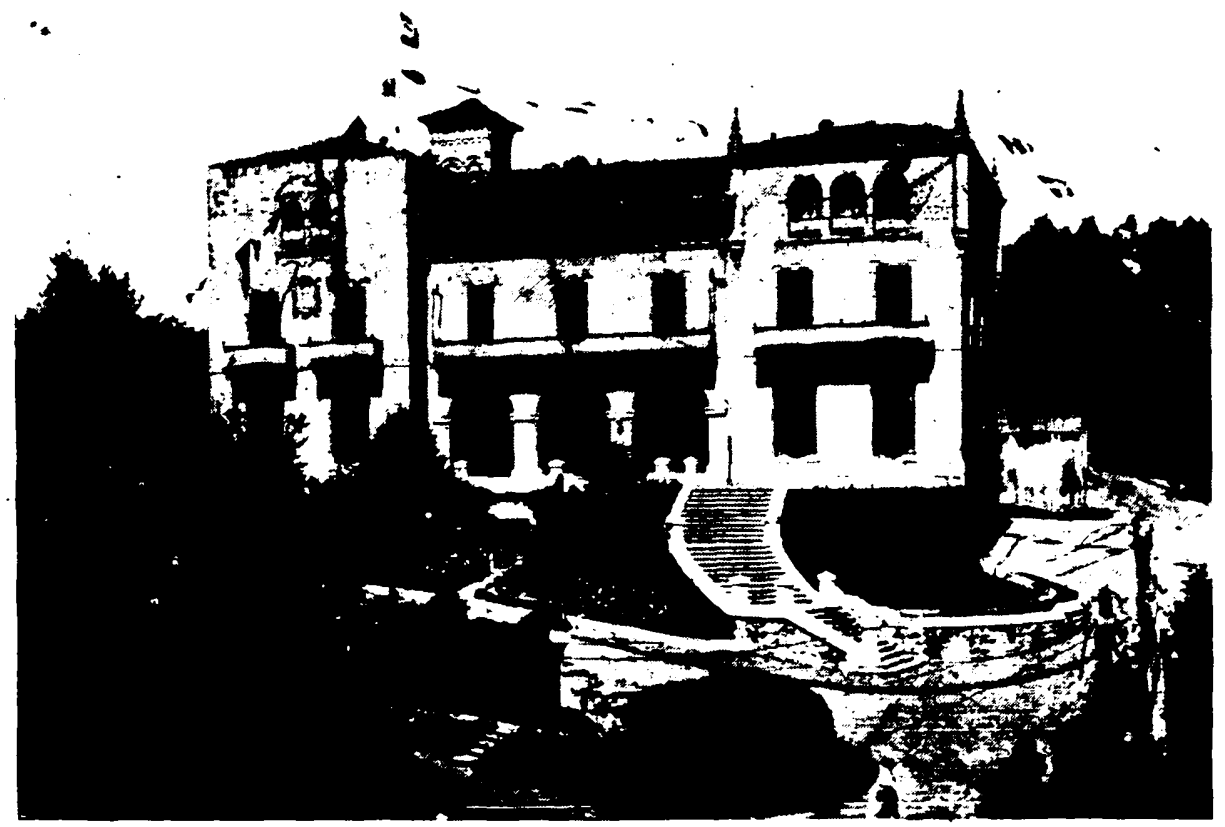

Fig. 4. - Nueva Casa Consistorial inalugurada en febrero de 1928 , en las proximidades de la Iglesia de San Ignacio. 
REVL-1949, núm. 44. PEREZ MINGUEZ Y DEVILLOTA, LUIS. URBANISMO. LA ANTEIGLESIA D...

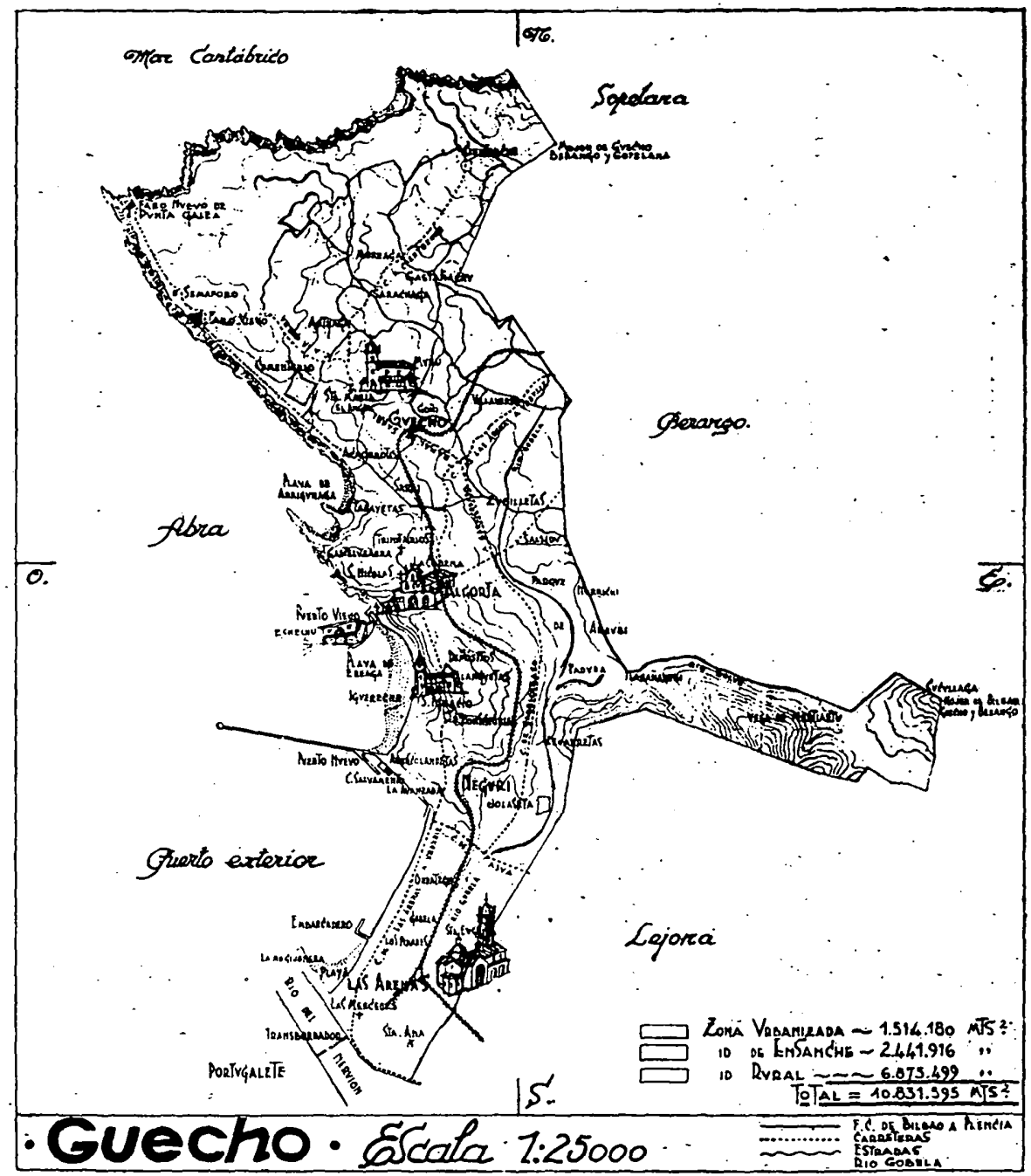




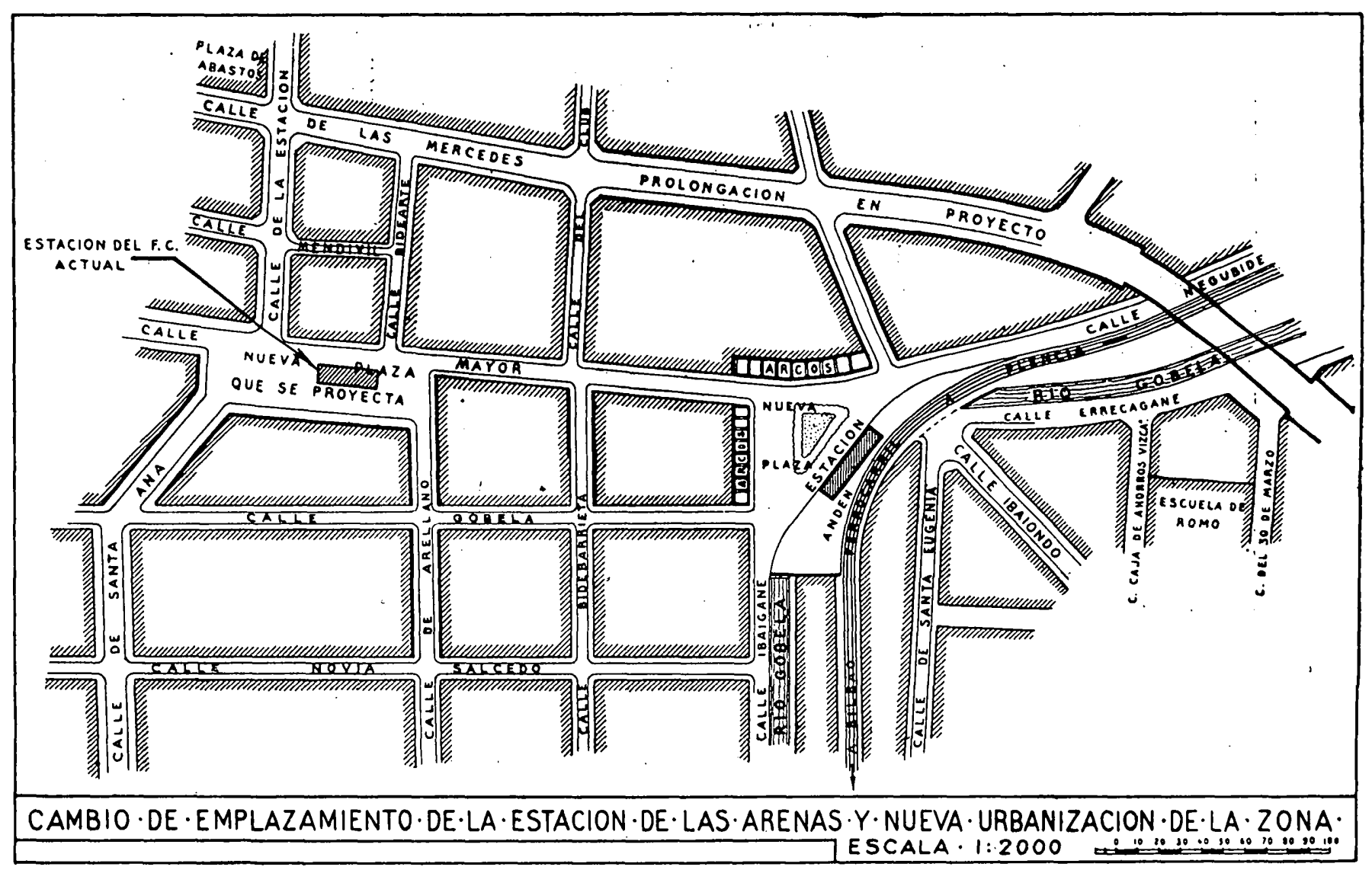


De todo lo expuesto se deduce que el Plan aprobado se estudió con un profundo respeto para el plano anterior, ha corregido sus defectos, indicados al comienzo, y, a no dudarlo, facilitará la urbanización de sus extensas zonas, al consentir mayor aprovechamiento del suelo, sin perjuicio de las normas más exigentes en urbanismo.

Tal ha sido el proceso seguido en la Ordenación del plano urbano de Guecho, que sin duda servirá para continuar el engrandecimiento de esta pintoresca Anteiglesia, que dentro del marco del Gran Bilbao ofrece sus residencias, jardines y playas para descanso y reposo. a los que se afanan en el trabajo diario en los pueblos que se asientan en la industrioșa Ría de Bilbao, y con su esfuerzo consiguen riqueza para España.

Jose J. Bta. Merino Urrutia

Alcalde de Guecho

\section{SANTANDER.-CURSO .SOBRE PROBLEMAS DE URBANISMO}

Organizado por la Delegación de la Secretaría de Educación Popular y el Ateneo de Santander, a mediados de marzo se inauguró un Curso de Conferencias sobre problemas urbanísticos de Santander y su Provincia, en la Universidad Internacional «Menéndez y Pelayow.

La primera Conferencia estuvo a cargo del Sr. Alcalde de la ciudaf, D. Manuel González Mesones, con arreglo al siguiente guión: Santander y sus tres catástrofes. Las reacciones santanderinas ante las adversidades. $\mathrm{El}$ incendio de febrero de 1941 y.sus problemas. El comercio permanece fiel a la ciudad. Fórmulas económicas de la reconstrucción. El problema de la vivienda. Ante una posible catástrófe económica de la ciudad.

El Arquitecto municipal D. Javier G. Riancho, pronunció la segunda disertación sobre Urbanismo y Estética.

El dia 23 pronunció -sú charla D. Ramiro Sáinz Martínez, sobre Ensanche de poblaciones. 
Al siguiente día habló el Abogado D. José García Revillo sobre los problemas jurídicos que planteó la reconstrucción de la ciudad.

La conferencia de D. José Pérez Bustamante, Presidente de la Diputación, versó sobre Geografía humana de la provincia de Santander.

El día 5 disertó D. Angel Hernández Morales, Arquitecto de la Diputación provincial, con arreglo al siguiente guión: Avance del plan comarcal de Santander. El núcleo urbano definido. Zonas: Urbanas confusas, de transportes, infustrial, residencial y veraneo, de colonias obreras rurales. Organización cívica y posible política municipal del suelo en esta útlima. Los accesos al núcleo urbano y enlaces con las distintas zonas indicadas.

Por último, la Conferencia de clausura estuvo a cargo del Gobernador civil de la Provincia, D. Joaquín Reguera Revilla, quien habló de la Historia de la Capital de la Montaña, la catástrofe última y su reconstrucción.

\section{UNA GRAN EXPOSICION DE LA HISTORIA URBANISTICA DE SANTANDER}

Por iniciativa del Excmo. Sr. Gobernador civil de la Provincia, se proyecta para el próximo veráno una gran exposición de la historia urbanistica de la Capital montañesa, al objeto de expresar, gráfica y fie'mente, al visitante, el proceso evolutivo y urbanístico de la ciudad, desde los tiempos de la vieja puebla hasta nuestros días, así como cuantas realidades en todos los aspectos se lograron en la provincia, recogiendo también ideas y proyectos del Santander futuro 


\section{EXTRANJERO:}

\section{ESTADOS UNIDOS}

Las soluciones al problema de la vivienda en Nueva York realizadas por la iniciativa privada, han planteado una serie de discusiones teóricas, sobre la conveniencia y acierto de los tipos de viviendas construídas y sobre todo en lo que se refiere a la altura y concentración de los bloques. El nuevo núcleo o «ciudad de Siuyvesant» ha sito a este respecto objeto de una enconada controversia entre el Técnico supervisor general de la Municipalidad de Nueva York, mister Robert Moses y el conocido tratadista Lewis Munford. El inierés desperiado en la opinión pública por esta discusión, mantenida a través de la Prensa americana, junto con la importancia de las cuestiones planteadas, la mayor parte de ellas subsistentes en casi todas las capitales del mundo, nos incitan a exponer primero lo que es esta nueva uciudad de Stuyvesant», y segundo, cómo se mantienen y defienden los dos puntos de viša di.erentes.

El nuevo núcleo residencial está emplazado entre la 1." Avenida y la Avenida C, próximo al East River, y en una zona de viviendas modestas e industrias y almacenes anejos a la linea por llaria del East River (fig. 1). La población que vivía en esia superficie de 30 hectáreas de extensión, era de 27.000 habitantes, o sea, 900 por hectárea en 1920, y bajó a 11.000 en el año 1943, fecha en que se iniciaron las obras.

El terreno es de forma rectangular, con 650 metros de longitud y 450 de ancho; estaba atravesato por cinco calles longitudinales y dos transversales, que lo subdividían en 18 manzanas; en el trazado actual se ha prescindido de las alineaciones antiguas y se han ordenato los bloques de vivienda con gran libertad (fig. 2), quedando el conjunto libre comp'etamente de cualquier tráfico de paso, y estableciéndose únicamente cuatro vías de carácter local, de acceso a las viviendas, en forma semicircular.

En el centro se ha instalado un pequeño parque de una hectárea, aproximadamente, de extensión alrededor del cual se disponen los 18 bloques de vivientas entre los que se sitúan algunos campos de juego infantiles, de dimensiones más reducidas. Próximos a las Avenidas periféricas se establecen algunas tiendas y garajes.

Los bloques se han estudiado acoplando tos tipos fundamenta- 


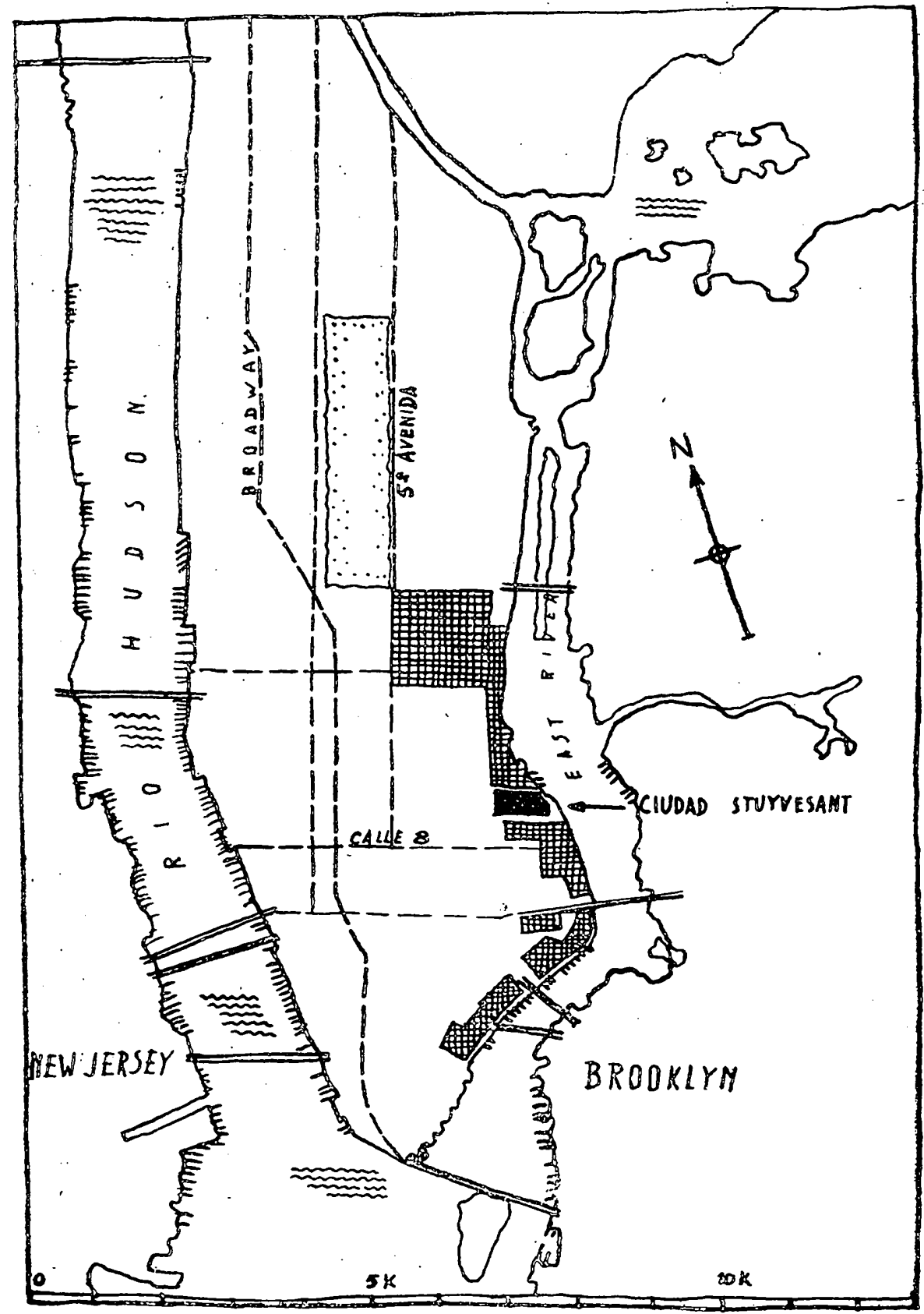

Fig. 1 . 
les: uno, en forma de cruz (fig. 3), y otro, en forma de codo (figura 4), con los cuales se ha resuelto la totalidad de las 9.000 viviendas con un número muy rejucido de plantas, facilitándose así la. construcción en serie con las ventajas de una mayor economıa al emplearse elementos prefabricados y un sistema de construcción mecanizada en gran escala.

La disposición en p'anta de los dos tipos es análoga. En la parte central van dos ascensores y dos escaleras Jando a un vestíbulo, ga-

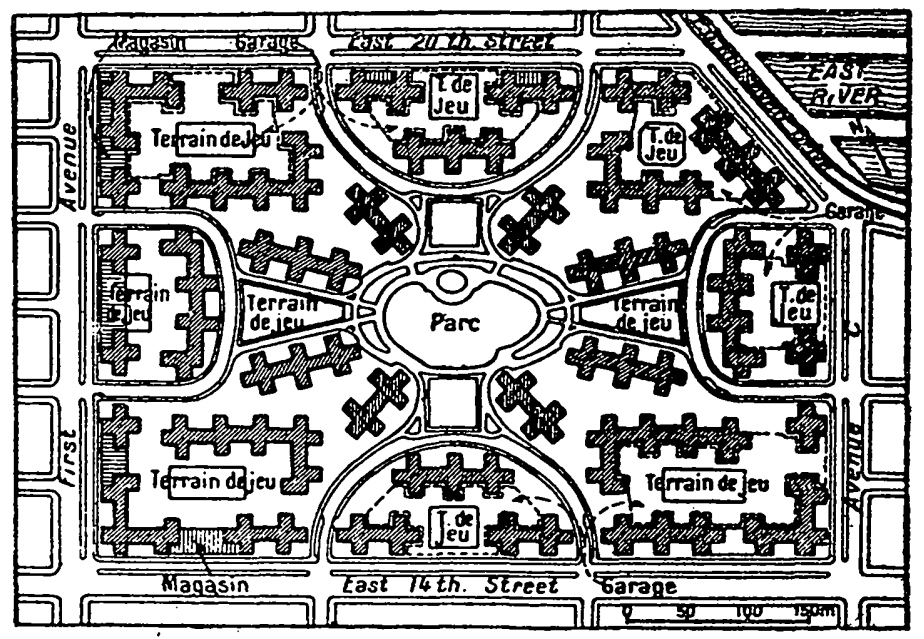

Fig. 2.

leria de'acceso, a ocho departamentos por planta, los cuales consisten en un cuarto de estar grande, uno o dos dormitorios, baño y cocina (figs. 3 y 4 ).

La construcción se inició por los garajes subterráneos, seis en total, que se utilizaron como almacenes de material; estos garajes, destinados para uso de los habitantes de la nueva ciudad, tienen capacidad para albergar $\mathbf{1 . 7 0 0}$ coches de turismo y se sitúan en las inmediaciones de las vías principales de acceso.

Los bloques destinados a viviendas son de 12 o 13 plantas con estructura y carpintería metálicas, y forjados je hormigón armado. Las cimentaciones son en su mayor parte sobre pilotes de hormigón." debido al firme irregular, sobre todo de la parte inmediata al rio.

La realización de los trabajos se llevó a un ritmo acelerado, ter- 
mirándose los 9.000 departamentos en menos de dos años. Esto fué: posible, en parte, por la rapidez en el desaloje de las edificacionesantiguas, debido a la declaración de obra de interés público y a las facilidıcies dadas por la Sociedad consiructora para el traslado de los. inquilinos a otros departamentos.

La financiación se realizó por una Sociedad de Seguros mediante-

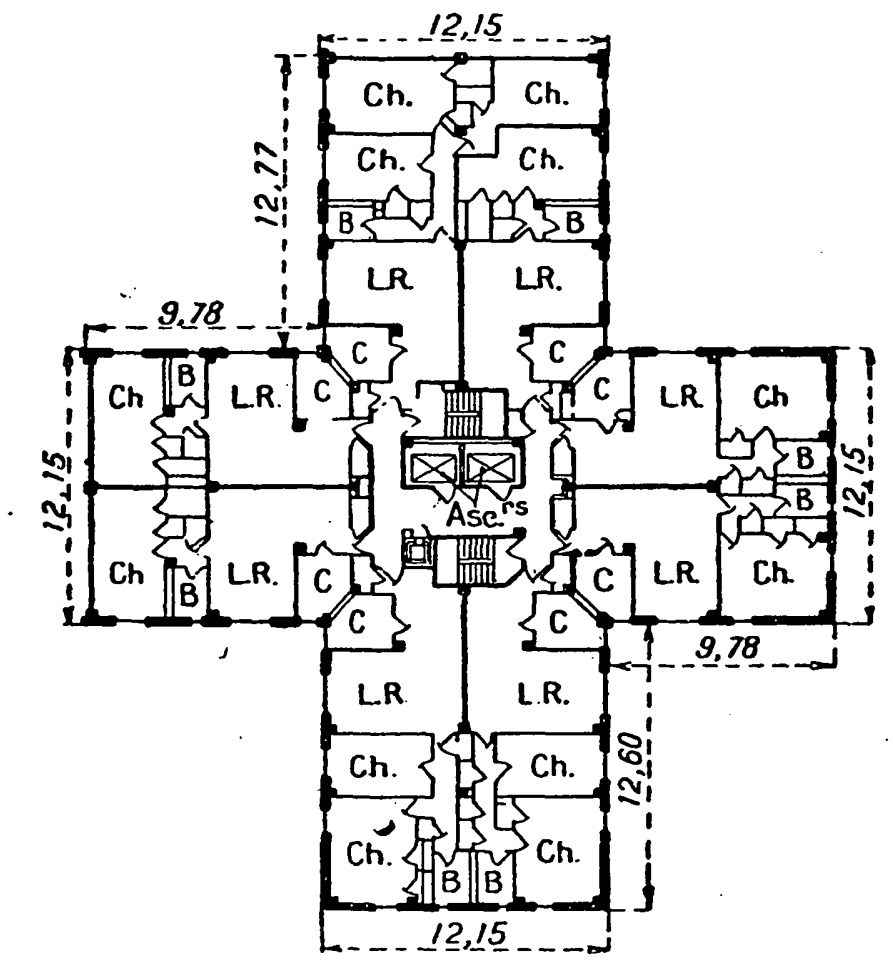

Fig. 3 .

un compromso previo con la Municipalidad de Nueva York, que autorizó la expropiación forzosa y fijó un tope a la renta de las nuevas vivienfas que permitiera, no obstante, un interés máximo del 6 por 100 al capiłal invertido.

El éxito de esta empresa estaba garantizado debido a la enorme demanda de yiviendas en los años siguientes a la terminación le la. guerra, prescntándose diez veces más solicitudes que apartamentos disponibles.

Por otra parte, es indulable que comparados los modernos blo- 
ques con las casas antiguas, representan un avance claro en lo que se refiere a comodidad e higiene general de la zona ; pero no obstante, teniendo en cuenta que esta nueva barriada no es un caso aislado, sin consecuencias importantes para el resto de la población, sino un elemenıo más dentro de un plan general de réorma del sector oriental de Manhattan (marcado con una cuadrícula en la fig. 1), y desti-

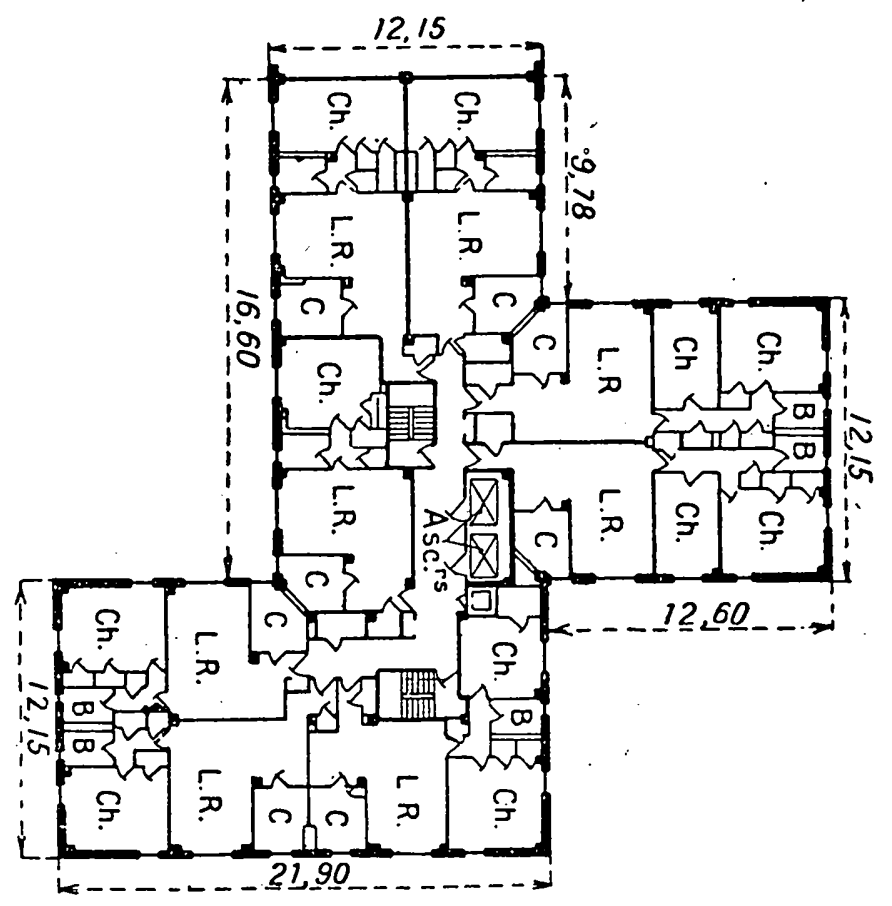

Fig. 4.

nado por su extensión a albergar a cientos de miles de habitantes, es por lo que se ha suscitado la cuestión, de indudable trascendencia, de si este sistema es lo suficientemente perfeccionado para ser aplicado en tan gran escala.

El argumento principal de Mumford en contra de Stugvesant es que, por resolver, sin gravamen para la economía municipal, el problema urgente de la vivienja, se crean núcleos congestionados con: densidades próximas a los 1.000 habitanıes por hectárea sin tener resueltos los problemas escolares en sus distintos grados, separación. adecuada de industrias incómodas, falta de campos deportivos de su- 
ficiente amplitud y carencia de establecimientos públicos de carácter sanitario, cultural, espiritual y administrativo, imprescindibles para el normal funcionamiento de una zona residencial acertadamente planeada.

El punto de vista del supervisor Moses se fundamenta en el éxito indudable obtenido, expresado claramente por la mismas personas que viven en "Stuyvesant) y numerosos visitantes de todas las clases sociales, y disculpando el exceso de densidad y la insuficiencia de algunos servicios públicos por la necesidad de resolver el problema sin los gastos cuantiosos que hubiera exigido el cumplimiento de tichas premisas urbanísticas.

Naturalmente, vista la cuestión desde un punto realista y a corto plazo, no deja de tener razón el señor Moses; pero consi.jerando que los problemas urbanos no deben enfocarse sino con criterio amplio, sobre todo en lo que se refiere al tiempo, no dejando a las generaciones que nos sigan problemas más graves que los que hemos tratado de resolver, parece ser más acertado procurar desligarse en lo posible de las presiones políticas interesadas en aplicar con preferencia medidas de fácil éxito y rápilos resultados, y decidirse por soluciones auténticas y realés, aunque no sean los iniciadores de éstas los que recojan los laureles que realmente se merecen. A este respecto conviene subrayar el efecto pernicioso que ejerce la influencia política, de naturaleza cambiante y discontinua, sobre los problemas de la técnica urbana necesitada; primero, de una gran competencia, debido a la complejidad progresiva de los problemas que plantea, y por lo tanto, muy difícil de improvisar; y segundo, de una continuidad normativa que dé solidez y consistencia a los planes que sucesivamente se van redactando.

Esta circunstancia apoya cada vez más la tendencia, desarrollada en varios paises, de separar claramente los campos y atribuciones propias de estos dos elementos decisivos en el desarrollo y ordenación de las poblaciones, el político con su alta misión directora de los problemas económicos y administrativos, que no debe verse distraído y complicado con los temas técnicos más laboriosos y detallados propios del otro sector importante formado por profesionales especializados.

Vemos, pues, que en la discusión surgida en torno a las nuevas ciudades neoyorquinas, existe, además de una cuestión técnica, resuelta con la brillantez y espectacularidad propios de los enormes 
recursos americanos, y que ellos mismos, en un deseo laudable de superación, encuentran en algunos puntos criticable; otro aspecto más profundo $\mathrm{y}$ trascendente, de indole política en su relación delicada con la técnica, y cuya resolución acertada o equivocada puede ser decisiva para el futuro de todas las ciudades del mundo, pues en todas ellas existe palpitante este mismo e importante problema.

\section{Pérez Ḿfnguez}

\section{Estudios y Estadísticas de la Vida Local de España}

Tomo I.-Administración Provincial. (Año 1943).

Un volumen de LXXII + 558 páginas.

Encuadernado: 50 pesetas.

Tомо II.-Administración Municipal. Volumen I: (Grandes Municipios. Más de 100.000 habitantes).

Un volumen de $\mathrm{XV}+\mathrm{r} .005$ páginas.

Encuadernado: 75 pesetas.

Tомо III.-Administración Municipal. Volumen II : Municipios de 15.001 a 100.000 habitantes.

Un volumen de XVI + 1.941 páginas.

Encuadernado: 200 pesetas.

Tомо IV.-Administración Municipal. Volumen III: Municipios de población inferior a $\mathbf{1 5 . 0 0 0}$ habitantes

A.-Población. Servicios. Un volumen de 554 págs., con profusión de gráficos, encuadernado: Precio 100 ptas.

Tомо V.-Administracion Municipal. Volumen IV: Totalidad de Municipios.

B.-Funcionarios. Un volumen de XXXII + 660 páginas, encuadernado: Precio 150 pesetas.

Los suscriptores a la Revista de este Instituto, y las Corporaciones en general, tienen una bonificación del 15 por 100 en todos los libros que publica el mismo. 